\title{
Possible Neuroprotective Effects of Crocin Against Motor and Neurochemical Changes in Rotenone Induced Animal Model of Parkinson's Disease
}

\author{
AHMED A. ABD AL-FATTAH, M.D. and ABEER A. ABO ZEID, M.D. \\ The Department of Medical Physiology, Faculty of Medicine, Tanta University, Tanta, Egypt
}

\begin{abstract}
Backgropund: Parkinson's Disease (PD) is considered a second most common neurodegenerative disease with slow and irreversible nigrostriatal degeneration with subsequent motor and behavioral deficits. Oxidative stress plays a key role in the pathogenesis of PD. Rotenone is a common pesticide inducing PD by the generation of oxidative stress.
\end{abstract}

Aim of Study: The aim of this study was to investigate the possible neuroprotective effects of crocin (saffron active compound) on rotenone induced Parkinson-like behaviors.

Material and Methods: 70 male Wister Albino rats were divided into 7 groups (10) per each. (1) Control group (normal saline); (2) Crocin 40mg/Kg; (3) Polyethylene Glycol (PEG) group (vehicle of Levodopa); (4) Rotenone group; (5) Rotenone + crocin $20 \mathrm{mg} / \mathrm{Kg}$; (6) Rotenone + crocin $40 \mathrm{mg} / \mathrm{Kg}$; (7) Rotenone + Levodopa $10 \mathrm{mg} / \mathrm{Kg}$. All agents were injected intraperitoneally once a day for 4 weeks. The neurobehavioral tests include open field, descent latency time in the bar test (seconds), forepaw stride length $(\mathrm{cm})$ and locomotor activity. In serum, the level of 8-hydroxydeoxyguanosine 8-OHdG was estimated. The level of Malondialdehyde (MDA), reduced glutathione (GSH), tumor necrosis factor alpha TNF-a, dopamine and nitrite/nitrate levels were measured in the brain tissue.

Results: Rotenone induced neurobehavioral deficits with elevation of brain MDA, brain TNF-a, Nitrite/nitrate level and serum $8-\mathrm{OHdG}$ and reduction of GSH, brain tissue dopamine. Crocin (20 or 40) improved these neurobehavioral deficits. Crocin (20 or 40) and L-DOPA decreased MDA, serum 8-OHdG, TNF-a and Nitrite/nitrate level and increased GSH and dopamine level. Crocin 40 had achieved potent effect compared with crocin 20.

Conclusion: Rotenone induced Parkinson-like behavior in rats. Crocin achieved a protective effect through reducing lipid peroxidation, anti-inflammatory and reducing DNA damage together with improvement of neurobehavioral deficits.

Key Words: Saffron - Crocin-Oxidative stress - Parkinson like behavior-DNA damage.

Correspondence to: Dr. Ahmed A. Abd Al-Fattah, E-Mail: Pacemaker107@gmail.com

\section{Introduction}

PARKINSON'S Disease (PD) is considered one of the most popular neurodegenerative disease whose prevalence increases with age [1].

The unique characteristics of PD include static tremor, alpha rigidity and sluggishness of movements. Other non-motor features include depression and sleep abnormalities [2]. The main pathological character of $\mathrm{PD}$ is neurodegeneration of the nigrostriatal dopaminergic pars compacta $(\mathrm{SNc})$, however, recently, serotonergic, noradrenergic, glutamatergic, GABAergic, and cholinergic systems may be included [3].

Rotenone, especially prolonged exposure, produces degeneration of nigeostriatal dopaminergic (DA) neurons with appearance of behavioral characteristics of PD [4].

A variety of studies had mentioned that oxidative stress possesses a major role in the pathogenesis of PD [5]

Free radicals and other Reactive Oxygen Species (ROS) accumulated from dopamine oxidation and metabolism, lipid peroxidation, altered mitochondrial activity, and reduction of the endogenous antioxidant systems contribute to PD appearance [6].

Crocin is a carotenoid substance which is water soluble and constitutes the active component of saffron. It has been postulated that crocin achieves many pharmacological functions such as antioxidative function [7,8], anti-inflammatory [9], reduces the incidence of cardio-vascular morbidities, amelioration of tumor cell proliferation, neuroprotection and hepatoprotection [6]. 
It has also been shown that the spice saffron, which contains powerful antioxidants such as crocin, protects nigral and retinal dopaminergic cells in an acute mouse model of Parkinson's disease. Taking in mind the role of oxidative and nitrosative stress in the pathogenesis of PD and the antioxidant and anti-inflammatory prosperities of crocin, the present study was labored to evaluate the effects of crocin on animal model of PD. Therefore, the aim of this study was to study the possible neuroprotective effects of crocin (saffron active compound) on rotenone induced Parkinson-like behaviors.

\section{Material and Methods}

Experimental animals: 70 Male albino rats of the local strains weighting $(210 \pm 20 \mathrm{~g})$ were purchased from the Faculty of Science, Tanta University. All animal experiments were undertaken with the approval of Ethical Animal Research Committee of Tanta University (from April 2018 till August 2018). The animals were housed at temperature $22 \pm 2^{\circ} \mathrm{C}$, exposed to alternate cycles of $12 \mathrm{~h}$ dark/ light throughout the study and fed chow ad libitum. All rats had free access to distilled water. Animals were kept for 2 weeks for acclimatization.

Chemicals: Crocin extract, Rotenone, Levodopa and Polyethylene glycol (PEG) were obtained from Sigma-Aldrich, Egypt.

Experimental design: Rats were randomly divided into 7 groups 10 per each. (1) Control group (normal saline); (2) Crocin 40mg/Kg; (3) Polyethylene Glycol (PEG) group (vehicle of Levodopa); (4) Rotenone group; (5) Rotenone + crocin 20 $\mathrm{mg} / \mathrm{Kg}$ [10] ; (6) Rotenone + crocin 40mg/Kg; (7) Rotenone + Levodopa $10 \mathrm{mg} / \mathrm{Kg}$ [11] . All agents were injected intraperitoneally once a day for 4 weeks.

\section{Open-field test:}

White wood, with a floor of $100 \times 100 \mathrm{~cm}$ divided by red lines into 25 lines equally. The height was $50 \mathrm{~cm}$ and was white painted. Illumination of the test room and the colony room was the same. Cleaned and dried apparatus was achieved. Placing each rat in the center and observing their behavior. The total number of squares crossed (total locomotion), the outer squares (peripheral locomotion) and inner squares (central locomotion) [12]

\section{Bar test for catalepsy:}

According to the method described by Costall and Naylor [13], the rats were placed with forelimbs on a horizontal thin bar $9 \mathrm{~cm}$ above and parallel to the base with a half rearing position. Removing one paw from the bar was considered the end of the test and the time was noted and recorded.

\section{Forepaw stride length:}

Rats were trained to walk in a narrow corridor that was lined by a clean white paper. The forepaws were dipped in red ink and rats were allowed to walk along the corridor again. The distance of stride length was estimated through measuring the distance between the fore prints [14]

Then, the animals were anesthetized by injection of a mixture of ketamine $(150 \mathrm{mg} / \mathrm{kg})$ and xylazine $(15 \mathrm{mg} / \mathrm{kg})$ I.P. and blood samples were collected from the heart into non-anti-coagulant containing tubes to obtain serum. Blood was allowed to clot for 30 minutes followed by centrifugation for 10 minutes at 5000rbm. Sera were separated and stored in aliquots at $-70^{\circ} \mathrm{C}$.

The hippocampus and the cortex were dissected bilaterally, washed and homogenized for estimation of the lipid peroxidation parameter (MDA) according to the method of Fernandez et al., 1997 [15] Reduced GSH was estimated according to the method of Moron et al., 1979 [16]. TNF- $\alpha$ was measured in accordance with Ye \& Johnson 1999 [17]. Dopamine level was measured according to the method described by Jacobowitz and Richardson; 1978 [18]. Nitrite/Nitrate level was measured by colorimetric method [19]

\section{Statistical analysis:}

All values were expressed as mean \pm SD. SPSS Version 16.0 was used for statistical analysis. Data were statistically analyzed using one-way ANOVA followed by Tukey-Kramer posttest for multiple comparisons. The values less than 0.05 were considered significant.

\section{Results}

\section{Descent latency time in the bar test (seconds):}

The mean value of the descent latency time in the bar test was $13.9 \pm 1.91,13.7 \pm 1.56$ and $13.6 \pm 2.31$ seconds in the control, crocin and PEG groups respectively. Rotenone group significantly increased the descent latency time compared with the control, crocin and PEG groups. Rotenone treated group with crocin $20 \mathrm{mg} / \mathrm{Kg}$ and $40 \mathrm{mg} / \mathrm{Kg}$ showed a significant decrease compared with the rotenone group with significant difference when comparing crocin $20 \mathrm{mg} / \mathrm{Kg}$ treated group with crocin $40 \mathrm{mg} / \mathrm{Kg}$ treated group. L-DOPA treated group showed significant reduction of descent latency time in the bar test compared with the rotenone group with insignificant change when comparing crocin $40 \mathrm{mg} /$ $\mathrm{Kg}$ treatment with L-DOPA treatment. 


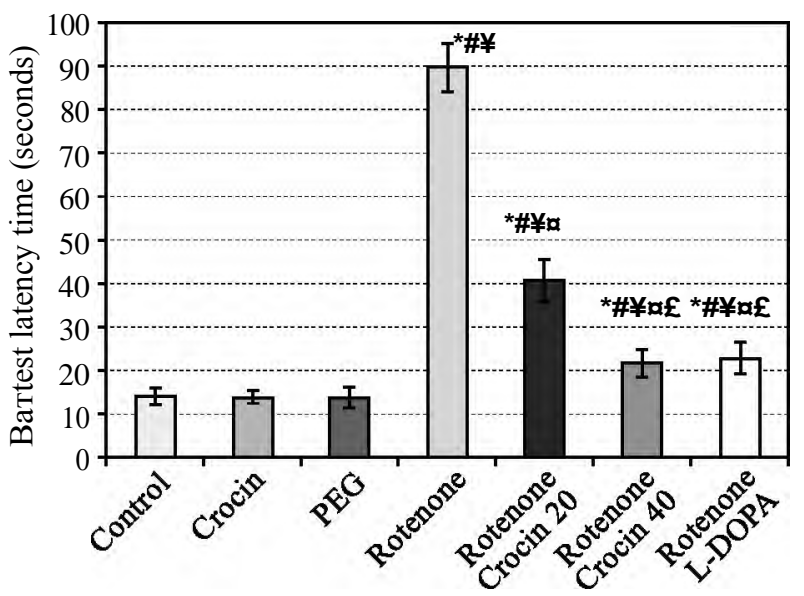

Fig. (1): Effect of crocin on descent latency time in the bar test (seconds).

: Significant compared with control.

a : Significant compared with Rotenone.

\# : Significant compared with crocin.

$£$ : Significant compared with Rotenone + Crocin 20

$¥$ : Significant compared with PEG.

¿ : Significant compared with Rotenone + Crocin 40 .

\section{Forepaw stride length $(\mathrm{cm})$ :}

The mean value of the forepaw stride length was $8 \pm 2,8 \pm 2.1$ and $8 \pm 1.9 \mathrm{~cm}$ in the control, crocin and PEG groups respectively. Rotenone group showed a significantly decrease of forepaw stride length compared with the control, crocin and PEG groups. Rotenone treated group with crocin 20mg/ $\mathrm{Kg}$ and $40 \mathrm{mg} / \mathrm{Kg}$ showed significant increase compared with the rotenone group with a significant difference when comparing crocin $20 \mathrm{mg} / \mathrm{Kg}$ treated group with crocin $40 \mathrm{mg} / \mathrm{Kg}$ treated group. L-DOPA treated group showed a significant increase of the forepaw stride length compared with the rotenone group. No significant change was observed when comparing crocin $40 \mathrm{mg} / \mathrm{Kg}$ treatment with L-DOPA treatment.

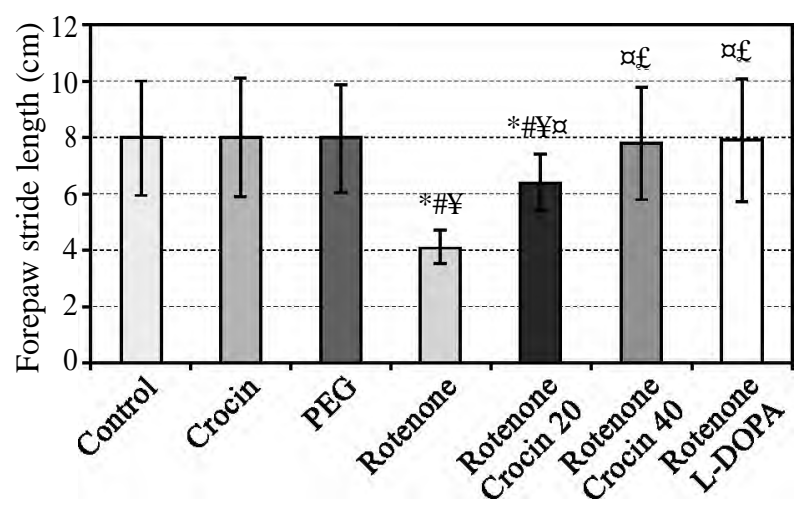

Fig. (2): Effect of crocin on forepaw stride length (cm).

: Significant compared with control.

a : Significant compared with Rotenone.

\# : Significant compared with crocin.

$£$ : Significant compared with Rotenone + Crocin 20

: Significant compared with PEG.

Significant compared with Rotenone + Crocin 40
Effect of rotenone and crocin on locomotor activity:

Using open field test in the 1 st day did not reveal significant changes among the studied groups Fig. (3).

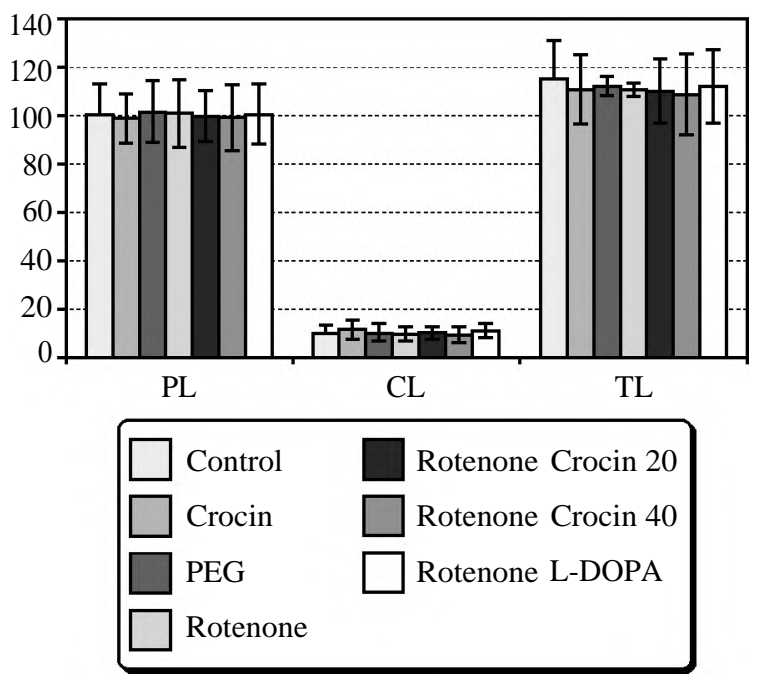

Fig. (3): Effect of rotenone and crocin on Total Locomotion (TL), Central Locomotion (CL) and Peripheral Locomotion (PL) in the 1 st day of the experiment.

At the end of the experiment, rotenone reduced the central, peripheral and total locomotion compared to the control, crocin and PEG groups. Crocin 20, 40 and L-DOPA plus rotenone increased the peripheral, the central and the total locomotion compared to the control group Fig. (4).

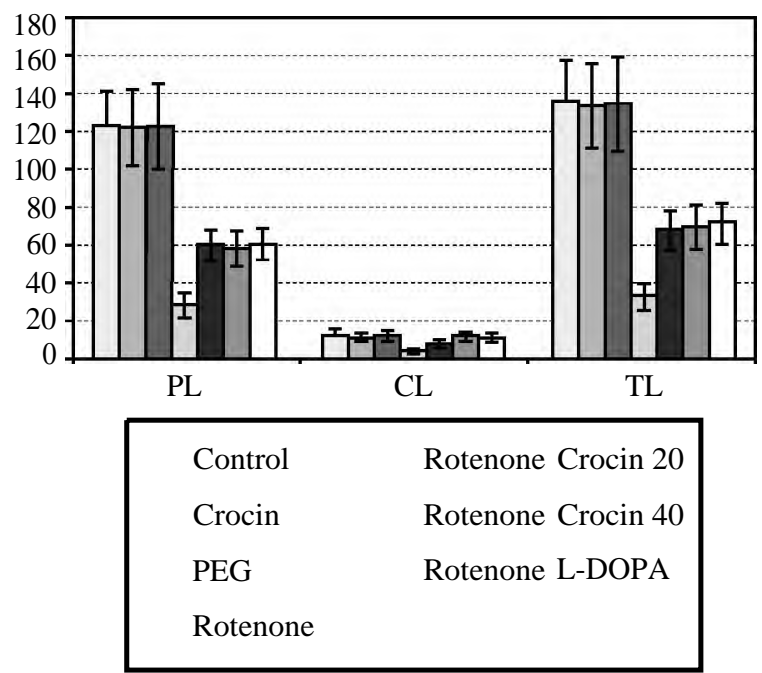

Fig. (4): Effect of rotenone and crocin on Total Locomotion (TL), Central Locomotion (CL) and Peripheral Locomotion (PL) at the end of the experiment.

\section{Lipid peroxidation:}

Rotenone administration markedly induced a significant increase of MDA level compared with control, crocin and PEG groups. A significant reduction of MDA was observed in rotenone treated 
(crocin 20, crocin 40 and L-DOPA) groups respectively. L-DOPA treated group showed a significant reduction of MDA compared with both crocin 20 and 40 treated groups.

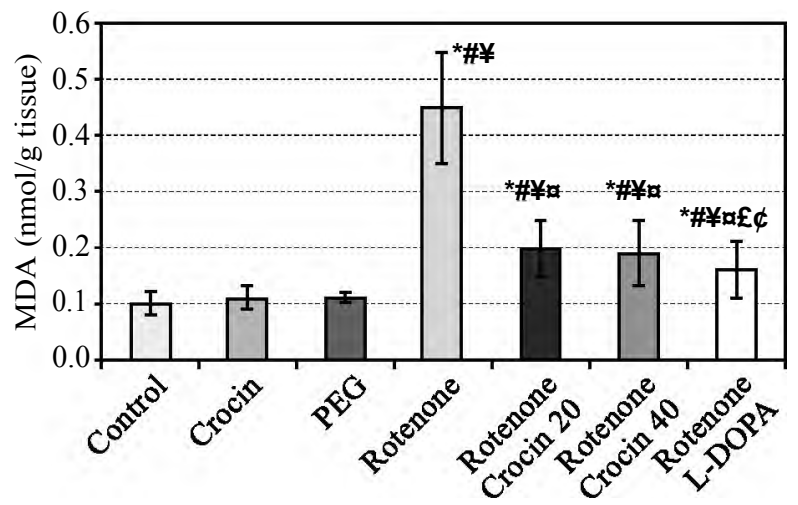

Fig. (5): Effect of crocin on lipid peroxidation.

* : Significant compared with control.

$\alpha$ : Significant compared with Rotenone.

\# : Significant compared with crocin.

$£$ : Significant compared with Rotenone + Crocin 20

¥ : Significant compared with PEG.

c : Significant compared with Rotenone + Crocin 40

\section{Effect of crocin on reduced GSH:}

Rotenone decreased significantly the level of GSH compared with control, crocin and PEG groups. Rotenone treated groups with crocin $20 \mathrm{mg} / \mathrm{Kg}, 40 \mathrm{mg} / \mathrm{Kg}$ and L-DOPA significantly restored the content of GSH. L-DOPA achieved a significant elevation of GSH compared with both crocin 20 and crocin 40 treated groups.

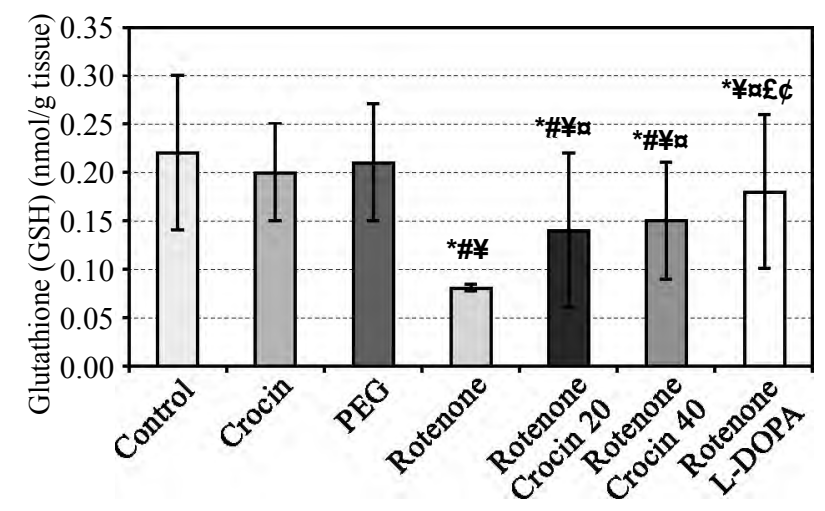

Fig. (6): Effect of crocin on reduced glutathione.

\footnotetext{
* : Significant compared with control.

a : Significant compared with Rotenone.

\# : Significant compared with crocin.

$£$ : Significant compared with Rotenone + Crocin 20 .

$¥$ : Significant compared with PEG.

$\notin$ : Significant compared with Rotenone + Crocin 40 .
}

\section{Effect of crocin on TNF-a:}

There was a significant increase of TNF- $a$ in rotenone treated group compared with control, crocin and PEG groups. Administration of crocin
20 , crocin 40 and L-DOPA reduced significantly this rotenone induced elevation of TNF- $a$. The TNF-ct was still higher after L-DOPA treatment compared with crocin treated groups in both doses.

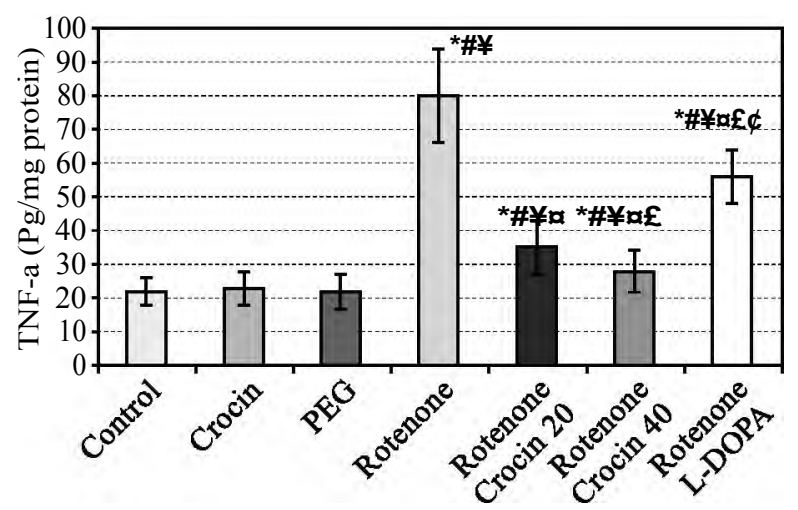

Fig. (7): Effect of crocin on inflammation.

\footnotetext{
* : Significant compared with control.

a : Significant compared with Rotenone.

\# : Significant compared with crocin.

$£$ : Significant compared with Rotenone + Crocin 20.

$¥$ : Significant compared with PEG.

c : Significant compared with Rotenone + Crocin 40 .
}

\section{Brain tissue dopamine level:}

Rotenone decreased significantly the dopamine level compared with control, crocin and PEG groups. Rotenone treated groups with crocin $20 \mathrm{mg} /$ $\mathrm{Kg}, 40 \mathrm{mg} / \mathrm{Kg}$ and L-DOPA significantly restored the content of dopamine. Dopamine level was significantly higher in crocin 40 treated group compared with crocin 20 treated one. Dopamine level restoration was more pronounced in L-DOPA treated group as dopamine level was significantly higher in this group compared with rotenone treated with crocin in both doses.

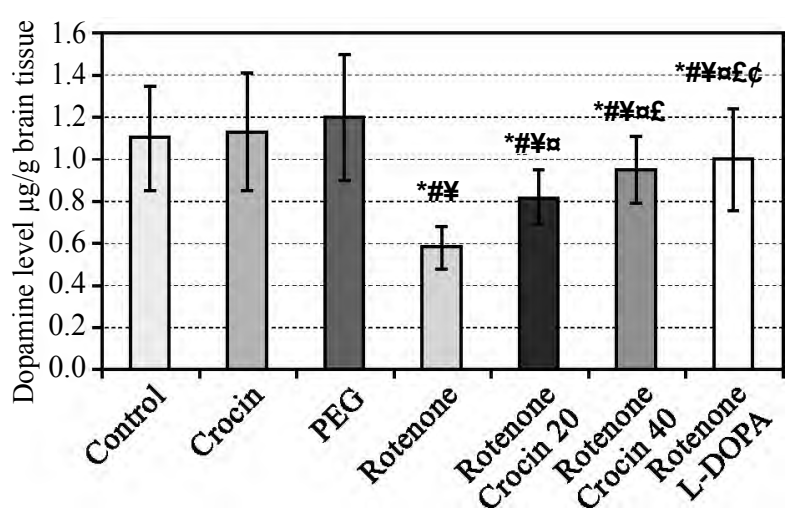

Fig. (8): Effect of crocin on brain dopamine level ( $\mu \mathrm{g} / \mathrm{g})$.

\section{Effect of crocin on DNA damage:}

Rotenone increased significantly the level of 8-hydroxy- 2 deoxyguanosine (8-OHdG) compared with control, crocin and PEG groups. Rotenone 
treated groups with crocin $20 \mathrm{mg} / \mathrm{Kg}, 40 \mathrm{mg} / \mathrm{Kg}$ and L-DOPA significantly reduced this elevation. 8OHdG level was still significantly higher in rotenone treated with crocin and L-DOPA compared with control, crocin and PEG groups. 8-OHdG was significantly lower in L-DOPA treated group compared with Crocin 20 and 40 treated groups.

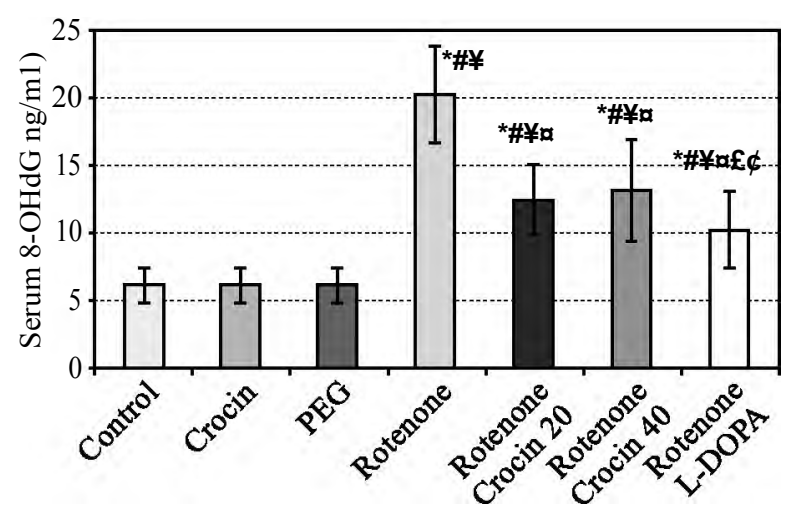

Fig. (9): Effect of crocin on Serum 8-OHdG level.

: Significant compared with control.

: Significant compared with Rotenone.

\# : Significant compared with crocin.

$£$ : Significant compared with Rotenone + Crocin 20 .

: Significant compared with PEG.

c : Significant compared with Rotenone + Crocin 40

\section{Nitrite/nitrate level:}

Rotenone increased significantly the level of Nitrite/nitrate compared with control, crocin and PEG groups. Rotenone treated groups with crocin $20 \mathrm{mg} / \mathrm{Kg}, 40 \mathrm{mg} / \mathrm{Kg}$ and L-DOPA significantly reduced this elevation. Nitrite/nitrate level was still significantly higher in rotenone treated with crocin and L-DOPA compared with control, crocin and PEG groups. Nitrite/nitrate level was significantly lower in L-DOPA treated group compared with crocin 20 and 40 treated groups and in crocin 40 treated compared with crocin 20 treated groups.

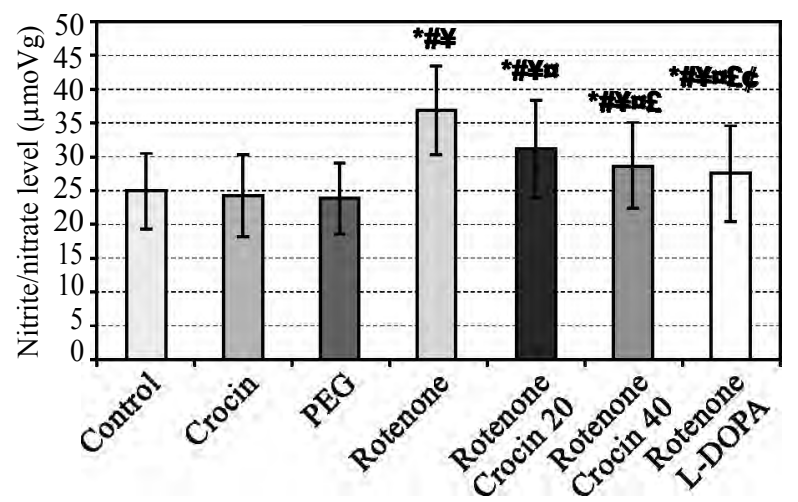

Fig. (10): Effect of crocin on brain nitrite/nitrare level.

: Significant compared with control.

: Significant compared with Rotenone.

: Significant compared with crocin.

: Significant compared with Rotenone + Crocin 20

: Significant compared with PEG.

: Significant compared with Rotenone + Crocin 40

\section{Discussion}

This study revealed that rotenone treated animals developed cataleptic behavior and impairment of the motor coordination compared with the control and the crocin treated groups. This confirmed that there was a loss of dopaminergic cells in the substantia nigra. The same had been reported by Dijkstra et al. [20].

Motor disruption in rotenone rat model of Parkinsonism was attenuated by using antioxidants [21]. Catalepsy is considered an important marker of nigrostriatal damage and can be induced by rotenone. This cataleptic behavior is linked to the dopaminergic nigrostriatal degeneration.

The open field test had indicated that rotenone reduced the central, peripheral and total locomotion compared with the control and crocin groups. Crocin 20 and $40 \mathrm{mg} / \mathrm{kg}$ as well as L-DOPA treatment had improved this impairment of locomotion. These results were supported by El-Horany and his followers \& Hosseini and his followers [22,23] L-DOPA treatment had reversed the deficits related to nigrostriatal degeneration [24]

Oxidative stress is considered an important step in aging and neurological disorders [25]. It can be induced by hypoxia or hyperoxia, leading to an increased free radical formation. The mitochondria is the main organelle that produce free radicals [26].

Brain tissue is more susceptible to oxidative stress than other tissues as it has a high metabolic activity, high oxygen consumption and presence of enhanced iron level leading to reduction of $\mathrm{H}_{2} \mathrm{O}_{2}$ to form the highly reactive hydroxyl radical [27].

Lipid peroxidation is the process of oxidative destruction leading to impaired membrane integrity and function and inactivation of membrane bound enzymes. Oxidative stress produced by free radicals and lipid peroxidation was considered an important step in the pathogenesis of Parkinsonism [28].

During oxidative stress, there is accumulation of oxidants and formation of TBARS [29]. The brain has less pronounced antioxidant mechanism and is rich in polyunsaturated fatty acids so, the brain is sensitive to oxidative damage.

In this study, there was a significant increase in MDA level in rotenone induced PD. Treatment with crocin reduced this elevation significantly and this effect refers to the corcin antioxidant activity as evidenced by increased enzymatic and GSH availability [30]. Chen and his team had stated 
that crocin, the major constituent derived from saffron, has different pharmacologic properties such as antioxidant activity [7].

The endogenous antioxidant systems consist of enzymatic (SOD, catalase and GPx) and nonenzymatic GSH that neutralizes the oxygen free radicals that leads to oxidative stress, if the antioxidant system is compromised [31]. Disruptions of the antioxidant system such as GSH have been documented in the PD brain [33]. The reduction of the GSH content occurred to minimize the delirious consequences of oxidative damage. A fault of one or more components of the antioxidant systems particularly, GSH is a key factor in the etiology of PD.

Inflammation is involved in the pathogenesis of Parkinsonism and this is followed by microglial activation. Microglial activation induces a variety of mediators particularly, NO and inflammatory cytokines and all contribute in the pathogenesis of $\mathrm{PD}$ and even its progression [23].

NO generation resulting from increased gene expression of induced NOS is followed by iNOS enzyme activation with subsequent contribution to the inflammatory process [34].

Crocin administration significantly reduced the inflammatory markers especially TNF-a. Tumor necrosis factor-alpha is considered a central cytokine involved in inflammation, immunity and cellular organization. The cytotoxicity of TNF- a is achieved by overproduction of ROS that threatens the cellular components such as protein, lipids, and DNA [35]. Crocin anti-inflammatory activity is through the inhibition of $\mathrm{m}$ RNA expression for TNF-a [36].

Rotenone decreased significantly the dopamine level compared with control, crocin and PEG groups. Rotenone treated groups with Crocin 20mg/ $\mathrm{Kg}, 40 \mathrm{mg} / \mathrm{Kg}$ and L-DOPA significantly restored the content of dopamine. Dopamine level restoration was more pronounced in L-DOPA treated group as dopamine level was significantly higher in this group compared with rotenone treated with crocin in both doses.

Crocin produced pronounced release of dopamine in rat brains. Crocin interacts with NMDA (N-methyl-D-aspartate) glutamate receptor sites of the brain to induce dopamine release. Crocin improves memory, and inhibits neuronal degeneration and this may be because of the ability of the extract to induce dopamine and/or glutamate release [35]
Dopaminergic neurons damage is a complicated process and several factors are responsible for this damage including oxidative, and nitrosative stress as evidenced by increased nitrite/nitrate level, mitochondrial dysfunction, inflammation and cytotoxicity. It has been postulated that reactive Nitrogen Species (RNS) play an important role in the achievement of dopaminergic damage. Rotenone increased the level of the nitrite, stable NO metabolite. Crocin administration reduced this rotenone induced elevation. Nam et al., [9] had been reported that crocin attenuated the NO and NOS activity. Crocin could be effective in attenuating nitrosative stress in rotenone animal model of Parkinsonism [23]

Mirmosayyeb et al., had postulated that crocin suppressed lipopolysaccharide (LPS)-induced nitrite from microglial cells with subsequent protection from LPS-induced cytotoxicity [36]

Disruption of homeostasis of inflammatory cytokines especially TNF- a could lead to immune system dysfunction and inflammation. Hyperactivity of B-cells and T-cells results in increased cytokine level [37]

In this study, rotenone increased the DNA damage as manifested by elevated serum 8 -OHdG. In general, very little is known about DNA damage in PD [38]

Rotenone induced mitochondrial dysfunction and oxidative stress as pronounced in our study. The unique property of mitochondria is the procession of their DNA (mt DNA) that is different from nuclear DNA in a way which makes it vulnerable to damage. Essential mitochondrial functions including oxidative phosphorylation, $\mathrm{Ca}++$ buffering, and apoptosis are influenced by mt DNA mutations, resulting in the onset of the CNS diseases particularly PD [39]. Crocin administration reduced the level of serum 8-OHdG and this could be attributed to its antioxidant property or up-regulation and down-regulation of p53 and other transcription factors [40].

Different factors are included in the development of cognitive, motor and behavioral changes in PD like oxidative, nitrosative stress with imbalance in NO generation, cholinergic system dysfunction, inflammation and apoptosis [41]

Rotenone induced loss of Tyrosine Hydroxylase (TH) positive neurons and reduced the expression of $\mathrm{TH}$ proteins. $\mathrm{TH}$ is a rate limiting enzyme of dopamine biosynthesis and converts tyrosine into L-DOPA [42] . At the same time, oxidative stress 
contributes the occurrence of dopaminergic neurons degeneration. Inflammation and apoptosis had been suggested to be responsible for dopaminergic neurons degeneration. Crocin has a potent antiinflammatory and anti-oxidative effect.

Crocin has the ability to induce dopamine and glutamate release. Unfortunately, we did not measure the changes of the regional level of neurotransmitters. This needs additional research to clarify this point.

\section{Conclusion:}

Crocin protected against rotenone model of Parkinsonism due to reduction of oxidative and nitrosative stress, proinflammatory cytokines and DNA damage. Crocin may be a unique item in preventing behavioral and motor deficits accompanying Parkinsonism.

\section{Acknowledgements:}

This work was supported by the Genetic Coding Center of the Tanta University Educational Hospital.

\section{Contributions:}

Concept, design, definition of intellectual content, data acquisition, and statistical analysis: Ahmed A. Abdalfattah and Aber A. Abo Zeid, literature search, manuscript preparation, manuscript review, manuscript editing, and data analysis: Ahmed A. Abdalfattah; experimental studies: Ahmed A. Abdalfattah and Aber A. Abo Zeid. All authors have read and approved the final version of the manuscript.

\section{Conflict of interest:}

The authors declare that they have no conflict of interest.

\section{References}

1- PRINGSHEIM T., JETTE N., FROLKIS A. and STEEVES T.D.: The prevalence of Parkinson's disease: A systematic review and meta-analysis. Mov. Disord, 29: 1583-90, 2014.

2- RODRIGUEZ-OROZ M.C., JAHANSHAHI M., KRACK P., LITVAN I., MACIAS R., BEZARD E., et al.: Initial clinical manifestations of Parkinson's disease: Features and pathophysiological mechanisms. Lancet Neurol., 8: 1128-39, 2009.

3- BRICHTA L., GREENGARD P. and FLAJOLET M. Advances in the pharmacological treatment of Parkinson's disease: Targeting neurotransmitter systems. Trends Neurosci., 36: 543-54, 2013.

4- BETARBET R., SHERER T.B., MACKENZIE G., GARCIA-OSUNA M., PANOV A.V. and GREENAMYRE J.T. Chronic systemic pesticide exposure reproduces features of Parkinson's disease. Nat. Neurosci., 3: 1301-6, 2000.
5- BHAT A.H., DAR K.B., ANEES S., ZARGAR M.A., MASOOD A., SOFI M.A., et al.: Oxidative stress, mitochondrial dysfunction and neurodegenerative diseases; a mechanistic insight. Biomed. Pharmacother., 74: 101-10, 2015.

6- RAJAEI Z., HOSSEINI M. and ALAEI H.: Effects of crocin on brain oxidative damage and aversive memory in a 6-OHDA model of Parkinson's disease, Arq. Neuropsiquiatr., 74 (9): 723-9, 2016.

7- CHEN Y., ZHANG H., TIAN X., ZHAO C., CAI L., LIU Y., et al.: Antioxidant potential of crocins and ethanol extracts of Gardenia jasminoides Ellis and Crocus sativus L. a relationship investigation between antioxidant activity and crocin contents. Food Chem., 109 (3): 484-92, 2008.

8- RAJAEI Z., HADJZADEH M.A., NEMATI H., HOSSEINI M., AHMADI M. and SHAFIEE S.: Antihyperglycemic and antioxidant activity of crocin in streptozotocin-induced diabetic rats. J. Med. Food, 16: 206-10, 2013.

9- NAM K.N., PARK Y.M., JUNG H.J., LEE J.Y., MIN B.D. PARK S.U., et al.: Anti-inflammatory effects of crocin and crocetin in rat brain microglial cells. Eur. J. Pharmacol., 648: 110-6, 2010.

10- DORRI S.A., HOSSEINZADEH H., ABNOUS K., HASANI F.V., ROBATI R.Y. and RAZAVI B.M.: Involvement of brain-derived neurotrophic factor (BDNF) on malathion induced depressive-like behavior in subacute exposure and protective effects of crocin. Iran J. Basic Med. Sci., 18 (10): 958-66, 2015.

11- SANDHU K.S. and RANA A.C. : Evaluation of anti parkinson's activity of Nigella sativa (kalonji) seeds in chlorpromazine induced experimental animal model. Mortality, 22: 23, 2013.

12- LEILA M., HOSSEIN H., KHALIL A. and BIBI M.R. : Neuroprotective potential of crocin against malathioninduced motor deficit and neurochemical alterations in rats. Environmental Science and Pollution Research, https://doi.org/10.1007/s11356-017-0842-0, 2017.

13- COSTALL B. and NAYLOR R.: Catalepsy and catatonia and the predictability of the catalepsy test for neuroleptic activity. Psychopharmacology, 34 (3): 233-41, 1974.

14- TAYLOR T., GREENE J. and MILLER G.: Behavioral phenotyping of mouse models of Parkinson's disease. Behav. Brain Res., 211 (1): 1-10, 2010.

15- FERNÁNDEZ J., PÉREZ-ÁLVAREZ J.A. and FERNÁNDEZ-LÓPEZ J.A.: Thiobarbituric acid test for monitoring lipid oxidation in meat. Food Chem., 59 (3): 345-53, 1997.

16- MORON M.S., DEPIERRE J.W. and MANNERVIK B.: Levels of glutathione, glutathione reductase and glutathione S-transferase activities in rat lung and liver. Biochim. Biophys. Acta., 582 (1): 67-78, 1979.

17- YE S.M. and JOHNSON R.W.: Increased interleukin-6 expression by microglia from brain of agedmice. J. Neuroimmunol., 93 (1-2): 139-48, 1999.

18- JACOBOWITZ D. and RICHARDSON J.: Method for the raoid determination of norepinephrine, dopamine and serotonin in the same brain region. Pharmacol. Biochem. Behav., 8 (5): 515-9, 1978.

19- MONTGOMERY H. and DYMOCK J.: Colorimetric determination of nitric oxide. In Analyst, 86: 414-6, 1961. 
20- DIJKSTRA A.A., VOORN P., BERENDSE H.W., GROENEWEGEN H.J., ROZEMULLER A.J. and BERG W.D.: Stage-dependent nigral neuronal loss in incidental Lewy body and Parkinson's disease. Mov. Disord, 29 (10): 1244-51, 2014.

21- ZAFAR K.S., SIDDIQUI A., SAYEED I., AHMAD M., SALIM S. and ISLAM F.: Dose dependent protective effect of selenium in rat model of Parkinson's disease: Neurobehavioral and neurochemical evidences. J. Neurochem., 84: 438-46, 2003.

22- EL-HORANY H.E., EL-LATIF R.N., ELBATSH M.M. and EMAM M.N.: Ameliorative effect of quercetin on neurochemical and behavioral deficits in rotenone rat model of Parkinson's disease: Modulating autophagy (quercetin on experimental Parkinson's disease). J. Biochem. Mol. Toxicol., 30 (7): 360-9, 2016.

23- HOSSEINI M., RAJAEI Z., ALAEI H. and TAJADINI M.: The effects of crocin on 6-OHDA-induced oxidative/ nitrosative damage and motor behaviour in hemiparkinsonian rats. Malays J. Med. Sci., 23 (6): 35-43. 10, 2016.

24- CANNON J.R., TAPIAS V., NA H.M., HONICK A.S., DROLET R.E. and GREENAMYRE J.T.: A highly reproducible rotenone model of Parkinson's disease. Neurobiol. Dis., 34: 279-90, 2009.

25- MOREIRA P.I., SIEDLAK S.L., ALIEV G., ZHU X., CASH A.D., SMITH M.A. and PERRY G.: Oxidative stress mechanisms and potential therapeutics in Alzheimer disease. J. Neural. Transm., 112: 921-32, 2005.

26- SIVARAMAN P.: Oxidative stress in neurodegenerative conditions and the protective potential of a natural antioxidant, dietary saffron, Oxid. Antioxid. Med. Sci., V.4, Issue 3, 112-8, 2015

27- JENNER P.: Oxidative stress in Parkinson's disease. Ann. Neurol., 53: 26-36, 2003.

28- LITTELJOHN D., MANGANO E., CLARKE M., BOBYN J., MOLONEY K. and HAYLEY S.: Inflammatory mechanisms of neurodegeneration in toxin based models of Parkinson's disease. Parkinsons. Dis., 2011: 713517, 2011.

29- ALYA A., INES D.B., MONTASSAR L., NAJOUA G. and EL-FAZÂA S.: Oxidative stress, biochemical alterations, and hyperlipidemia in female rats induced by lead chronic toxicity during puberty and post puberty periods. Iran J. Basic Med. Sci., 18 (10): 1034-43, 2015.

30- UCHENDU C., AMBALI S.F., AYO J.O. and ESIEVO K.A.: The protective role of alpha-lipoic acid on longtermexposure of rats to the combination of chlorpyrifos and deltamethrin pesticides. Toxicol. Ind. Health, 33 (2): 159-70, 2017.

31- ANDERSON G. and MAES M.: Neurodegeneration in Parkinson's disease: Interactions of oxidative stress, tryptophan catabolites and depression with mitochondria and sirtuins. Mol. Neurobiol., 49: 771-83, 2014.

32- CELARDO I., MARTINS L.M. and GANDHI S.: Unravelling mitochondrial pathways to Parkinson's disease. Br. J. Pharmacol., 171: 1943-57, 2014.
33- NIRANJAN R.: The role of inflammatory and oxidative stress mechanisms in the pathogenesis of Parkinson's disease: Focus on astrocytes. Mol. Neurobiol., 49: 28-38, 2014.

34- Di MATTEO V., PIERUCCI M., BENIGNO A., CRESCIMANNO G., ESPOSITO E. and Di GIOVANNI G.: Involvement of nitric oxide in nigrostriatal dopaminergic system degeneration: A neurochemical study. Ann. N. Y. Acad. Sci., 1155: 309-15, 2009.

35- EL-GERBED M.S.: Protective effect of lycopene on deltamethrininduced histological and ultrastructural changes in kidney tissue of rats. Toxicol. Ind. Health, 30 (2): 160-73, 2014

36- YANG R., TAN X., THOMAS A.M., SHEN J., QURESHI N., MORRISON D.C. and VAN WAY C.W.: Crocetin inhibits mRNA expression for tumor necrosis factor- a, interleukin- 13 , and inducible nitric oxide synthase in hemorrhagic shock. JPEN J. Parenter. Enteral. Nutr., 30 (4): 297-301, 2006.

37- MIRMOSAYYEB O., TANHAEI A., SOHRABI H.R., MARTINS R.N., TANHAEI M., NAJAFI M.A., et al.: Possible role of common spices as a preventive and therapeutic agent for Alzheimer's disease. International Journal of Preventive Medicine, 156. 217, 8: 52017.

38- UMARE V., PRADHAN V., NADKAR M., RAJADHYAKSHA A., PATWARDHAN M., GHOSH K.K., et al.: Effect of Proinflammatory Cytokines (IL-6, TNF- a and IL-1 3 ) on Clinical Manifestations in Indian SLE Patients. Mediators Inflamm., Doi: 10.1155/2014/385297, 2014.

39- SANDERS L.H., JENNIFER M., HU X., PIER G.M., BRYAN C., DICKINSON B.C., et al.: Mitochondrial DNA damage: Molecular marker of vulnerable nigral neurons in Parkinson's disease. Neurobiol. Dis., 70: 21423, 2014.

40- MARKHAM A., BAINS R., FRANKLIN P. and SPEDDING M.: Changes in mitochondrial function are pivotal in neurodegenerative and psychiatric disorders: How important is BDNF? Br. J. Pharmacol., 171 (8): 2206-24, 2014.

41- NIEDZWIEDZ A., BOROWICZ H., JANUSZEWSKA L., MARKIEWICZ-GORKA I. and JAWORSKI Z.: Serum 8-hydroxy-2-deoxyguanosine as a marker of DNA oxidative damage in horses with recurrent airway obstruction. Acta. Vet. Scand., 58: 38, 2016.

42- TIWARI V. and CHOPRA K.: Resveratrol abrogates alcohol-induced cognitive deficits by attenuating oxidativenitrosative stress and inflammatory cascade in the adult rat brain. Neurochem. Int., 2 (6): 861-9, 2013.

43- ANUSHA C., SUMATHI T. and JOSEPH L.: Protective role of apigenium on rotenone induced rat model of Parkinson,s disease: Suppression of neuro inflammation and oxidative stress mediated apoptosis. Chem. Biol. Interact., 269: 67-79, 2017. 


\section{الآثار العصبية المحتملة من الكروسين ضل التغييرات الحمركية

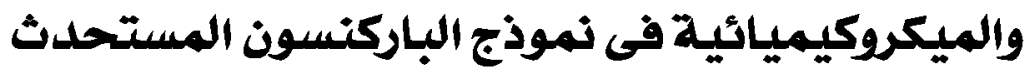 بواسطة الريتونون في الجرذانيان}

مقدمة: يعتبر مرض باركنسون (PD) ثانى آكثر الآمراض العصبية شيوعاً مع تنكس نيغرستيراتى بطى ولا رجعة فيه مع عجز حركى الإنى

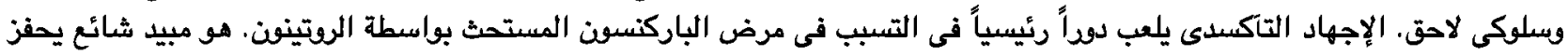

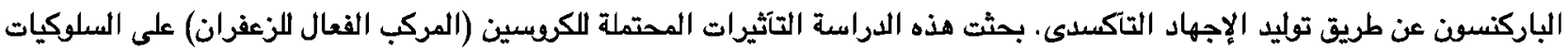
الثبيهة بالباركنسون التى يسبيها الروتينيون.

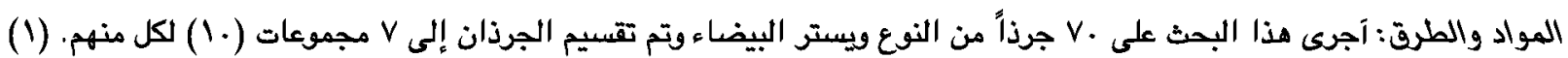

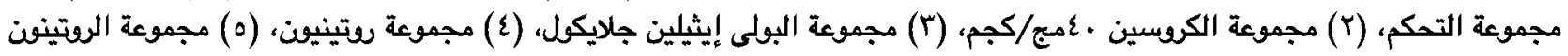

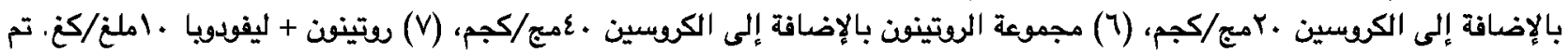

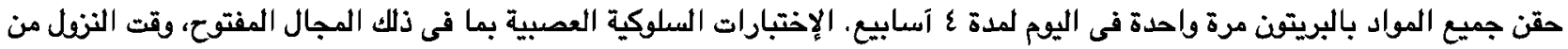

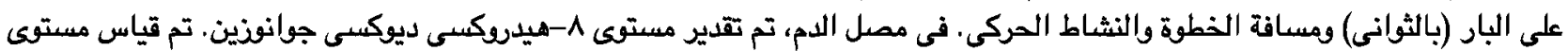

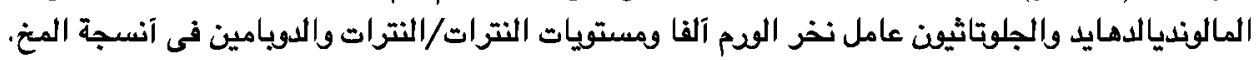

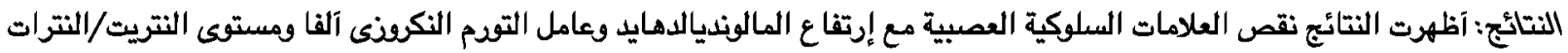

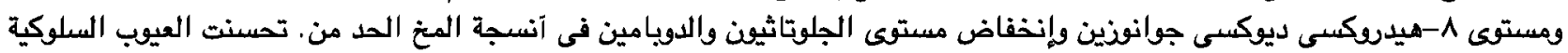

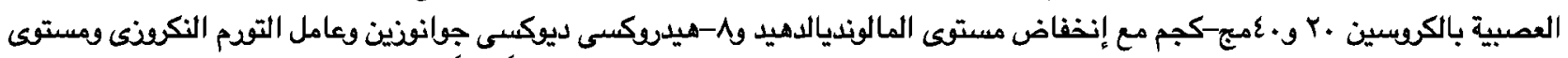

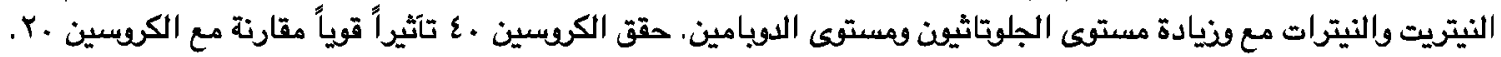

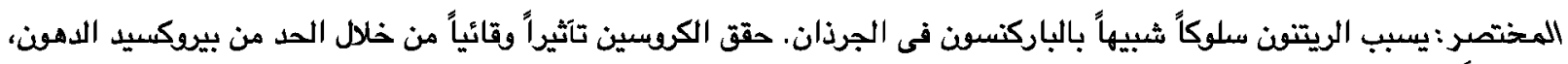

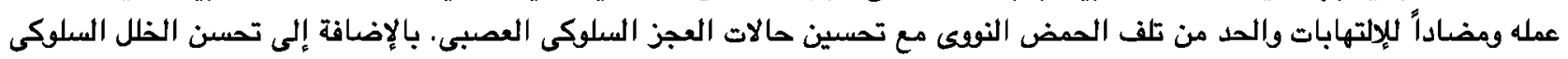

